\title{
A personagem formiga em fábulas de La Fontaine: uma abordagem em aulas de francês como língua estrangeira
}

\author{
Francinaldo de Souza Lima* \\ Josilene Pinheiro-Mariz ${ }^{* *}$
}

\begin{abstract}
Resumo: La Fontaine é referência quanto ao gênero fábula, seja pelo caráter crítico que elas possuem, seja por conseguirem atingir tanto o público adulto, quanto o infantil, dando vida aos animais. Neste trabalho, buscamos entender a partir de uma pesquisa qualitativa e documental, a crítica social implícita na personagem 'formiga'. Em seguida, apresentamos uma proposta de trabalho a ser realizada em aulas de língua francesa para iniciantes, evidenciando a importância do texto literário na didática de línguas estrangeiras e buscando mostrar como estabelecer uma relação harmônica entre o ensino de língua e a literatura. Escolhemos três fábulas de La Fontaine, tendo a formiga como um dos personagens, a saber: La cigale et la fourmi, La colombe et la fourmi e La mouche et la fourmi. Tomamos como referencial teórico os trabalhos de Pinheiro (2006) e PinheiroMariz (2007) em suas reflexões a respeito da importância do trabalho com texto poético em sala de aula e como este trabalho pode auxiliar no ensino e na aprendizagem de língua estrangeira, respectivamente. Percebemos que as fábulas em questão apresentam uma crítica social bastante atual, favorecendo a leitura literária em contexto de ensino de línguas, promovendo também a formação humana, além de propiciar estratégias para trabalhar com o léxico, dentre outras questões ligadas ao ensino. Esta proposta de trabalho leva o aprendiz a exercitar as competências de compreensão e expressão, tanto no eixo da oralidade, quanto da escrita; considerando-se, sempre, uma adequação que estimule uma formação completa do aprendiz.
\end{abstract}

Palavras-chave: Fábulas. Literatura. Francês Língua Estrangeira. Língua e Literatura.

\section{A FRENCH CLASS APPROACH TO THE ANT AS A CHARACTER IN LA FONTAINE'S FABLES}

ABSTRACT: La Fontaine is a reference when it comes to the genre of fables, not only for the critical feature they possess, but also for the ability to please both adults and youngsters, giving life to animals. In this work, by means of qualitative and documental research, we attempt to understand the social criticism implicit in the "ant" as a character. Then, we present a task proposal which can be applied to French classes for beginners, by highlighting the relevance of the use of literary texts in foreign language teaching, and trying to show how to establish a harmonious relationship between language teaching and literature. We selected three of La Fontaine's fables, with the ant as one of the characters, namely, The cicada and the ant, The dove and the ant and The fly and the ant. Our theoretical background is based on Pinheiro (2006) e Pinheiro-Mariz (2007), who offer insight on the importance of working with poetry in the classroom and how it can help foreign language teaching and learning. We noticed that the fables mentioned have very up-to-date social criticism, which is a helpful tool for the literary reading in the language teaching context, enhances human formation, and brings forth strategies for working with words and other topics related to teaching. This task proposal enables the learner to exercise his/her comprehension and expression competences, both in oral and written forms; always looking for ways to adapt the tasks in order to stimulate the learner's instruction as a whole.

Key-words: Fables. Literature. French as a Foreign Language. Language and Literature.

\section{Introdução}

No âmbito da didática do ensino de línguas, existem debates intensos a respeito da relação entre língua e literatura na formação dos aprendizes de línguas estrangeiras (LE),

\footnotetext{
* Estudante de Letras Português e Francês, da Universidade Federal de Campina Grande (UFCG), onde também é bolsista do Programa de Educação Tutorial (PET-Letras). francinaldodesouza@gmail.com

** Professora de língua e literaturas de língua francesa na Universidade Federal de Campina Grande (UFCG) e do Programa de Pós-Graduação em Linguagem e Ensino, da mesma instituição. jsmariz22@ @otmail.com
} 
sobretudo quando serão professores da língua aprendida. Os próprios manuais didáticos, em muitos casos, deixam de apresentar textos literários em suas páginas, privilegiando ora o ensino de gramática tradicional, ora a conversação simulada. Porém, aos poucos, tem se percebido que essa realidade vem sendo transformada e, assim, os defensores da inserção da literatura na sala de aula não só de LE, mas de língua materna (LM) também, têm sugerido propostas de trabalho e divulgado pesquisas da eficiência e da importância desse trabalho conjunto.

As fábulas de La Fontaine trazem uma forte crítica à sociedade europeia do século XVII, tendo os animais como personagens de suas histórias e inspiradas por outro grande fabulista, um grego do século VI a.C., Esopo. Segundo Oliveira (2007 apud. MONTEIRO, 2007), é na ironia das fábulas de La Fontaine que está o grande fator positivo da escrita do autor, uma vez que seus textos não apresentam grande originalidade temática.

Usufruindo dessa característica, este trabalho propõe apresentar, inicialmente, reflexões sobre a relação língua e literatura na história da didática de ensino de Francês Língua Estrangeira (doravante FLE), seguida de algumas considerações sobre a importância desse trabalho conjunto. Dentro desse panorama, traremos uma breve interpretação de três fábulas que apresentam a formiga como uma das personagens. São elas: La cigale et la fourmi, La colombe et la fourmi e La mouche et la fourmi. Um dos objetivos aqui é fazer uma leitura literária desses textos, bem como uma leitura da função social destes, a fim de responder a duas questões interligadas entre si. A resposta da primeira, "Qual é a crítica que La Fontaine faz à sociedade de sua época através da personagem 'formiga'?” nos direciona à segunda: "De que maneira poderá o docente de Francês Língua Estrangeira trabalhar com essas fábulas em suas aulas?”. Para responder ao último questionamento, trazemos uma proposta de trabalho com esses textos que pode ser aplicada em uma turma de estudantes de FLE em nível iniciante ou intermediário; configurando-se, assim, o segundo objetivo deste trabalho.

\section{A relação entre a língua e a literatura no ensino do FLE}

Nos séculos XVIII e XIX, a França experimentou um momento de grande efervescência cultural e política e construiu ao seu redor uma ideologia de sociedade modelo para o mundo. Em nome disso, a França montou uma "missão educadora" a fim de "guiar as outras populações (as não civilizadas) pelos caminhos do progresso e do desenvolvimento" (PINHEIRO-MARIZ, 2007, p.99). Essas “civilizações" estavam situadas, por exemplo, em 
regiões como a do norte do continente africano (onde se situam países como Tunísia, Argélia, Marrocos, entre outros).

Com a intenção de divulgar, (leia-se impor) para além do território francês essa língua tão perfeitamente clara e virtuosa, os responsáveis pelo seu tratamento, pureza e manutenção tiveram que empreender grandes esforços para fazer da língua francesa o que de fato queriam que ela fosse: uma língua universal, uma vez que a sua estrutura e sonoridade pareciam estar muito além da beleza que, para os filósofos, lhe era peculiar. A divulgação foi feita seguindo-se uma sistemática destruição das línguas regionais como o patuá, bem como das línguas estrangeiras, nos países onde a França se instalara com a sua "missão educadora" (PINHEIRO-MARIZ, 2007, p.100).

Vista como a língua pura e bela, desde o século XVIII, o Século das Luzes, o francês ganhou, com a criação da Aliança Francesa em 24 de Janeiro de 1884, um grande aliado na luta por sua expansão pelo mundo. $\mathrm{O}$ ensino da língua francesa estava ligado à seguinte ideologia: o que vinha da França era culto, belo, chique, padrão, de modo que através da língua fosse divulgada a imagem de um país moderno e avançado. Nesse contexto, era parte integrante desse método de promoção da cultura francesa, divulgar não só a língua, mas também os grandes artistas, como por exemplo, os grandes escritores. É nesse momento que se percebe a entrada da literatura no ensino da língua francesa.

Todo o cuidado com o ensino da língua resulta, inevitavelmente, em cuidado ainda maior com o ensino da literatura pelo fato de elas estarem relacionadas e, também, por que a literatura era considerada como a essência da língua e da cultura francesa. Um pensamento tradicional sobre o ensino da literatura francesa mostra que a cultura e a língua francesa eram ensinadas pela sua excelência, como uma forma de se fazer conhecer os monumentos da tradição, as instituições e ainda mais as obras-primas artísticas e literárias do país (PINHEIRO-MARIZ, op. cit., p. 102).

Assim, a relação entre língua e literatura esteve presente desde o início do ensino tanto do FLM (Francês Língua Materna) quanto do FLE, inclusive nos manuais didáticos utilizados em sala de aula. Porém, com os avanços nas teorias e metodologias de ensino, a língua enquanto código (ou seja, encarada pela visão estruturalista de língua) acabou afastando aos poucos a literatura deste cenário, evento que pode ser visto até hoje, quando se analisa os manuais didáticos de FLE. A grande questão que fica é: quais as causas dessa exclusão e da quebra da relação entre língua e literatura no ensino de FLE?

Diversas são as razões para essa separação; dentre as principais questões, destaque-se o fato de que desde os primórdios da sistematização do ensino da língua francesa, houve continuamente uma inquietação em se oferecer a literatura para alunos com sólidos conhecimentos da língua. Outro fator que marcou essa separação foi a associação da imagem do povo francês à cultura 
e ao refinamento. Tais características que podiam ser vistas através da literatura, "a língua, na sua melhor manifestação", podendo ainda se confirmar como uma forma explícita de cultura de um povo "civilizado". Assim, as metodologias que surgiram com o propósito de sistematizar esse ensino só corroboraram a situação, afastando, sucessivamente, o ensino da literatura em língua estrangeira francesa do ensino da própria língua francesa. (id. ibid., p. 113). (aspas da autora).

Muito provavelmente, foi essa ideia de uma língua perfeita e de uma literatura que retrata características de um povo "civilizado", que promoveu o afastamento entre essas duas grandes áreas de Letras: Língua e Literatura. Ora, se a literatura é "a língua na sua melhor manifestação", por certo, a literatura estaria muito além da língua, que seria apenas um de seus componentes, mesmo sendo "bela língua". Sob a nossa ótica, a busca por uma abordagem que enfoque na não dissociação desses dois domínios é de necessidade capital para qualquer profissional desta grande área. Por essa razão, buscamos um caminho harmônico que realce as benesses da literatura, com o propósito de reforçar os benefícios da aprendizagem da língua estrangeira francesa.

\section{Por um ensino harmônico entre língua e literatura: benefícios às aulas de leitura}

Como já vimos, (re)pensar em estabelecer uma harmonia entre língua e literatura no ensino de LE é voltar às origens desse ensino, já que é algo arraigado. Essa é, pois, uma realidade do ensino de LE, algo que pode ser observado tanto no ensino da língua francesa, quanto no domínio da língua inglesa e da italiana, por exemplo. (PINHEIRO-MARIZ, 2007; VALENTE; PINHEIRO, 2008; SANTORO, 2007, respectivamente).

Os estudos supracitados têm mostrado que o texto literário (doravante TL) pode ser trabalhado em sala de aula de diversas maneiras: seja para ensino de gramática, de vocabulário, embora muito se critique a respeito dessa forma de abordagem. Faz-se necessário ressaltar que o TL não deve ser utilizado como um simples pretexto para o ensino de elementos linguísticos, no entanto, a sua riqueza polissêmica não pode ser deixada de lado. Além disso, elementos estruturais relacionados à literatura, como a rima e a métrica da poesia e outros elementos essenciais da narrativa, também podem incitar o aprendiz a perceber o outro e o mundo do outro através da língua (do outro) em estudo; ou seja, trata-se de um documento especial para trabalhar o envolvimento com a língua e com e a cultura estrangeira. Além do mais, conforme chamam a atenção Valente e Pinheiro (2008), quando o ensino de língua estrangeira está associado a elementos lúdicos que levem o aprendiz a se divertir enquanto aprende, pode haver uma aceleração da aprendizagem uma vez que as aulas se 
mostrarão menos enfadonhas e cansativas e, nesse momento, pode-se estimular a fruição literária (BARTHES, 1973). "A literatura pode perfeitamente cumprir esse papel, motivando o aluno, aumentando seu interesse pela língua e agilizando seu processo de aprendizagem" (VALENTE; PINHEIRO, 2008, p. 52).

Promover aulas de leitura com uma interface mais interativa, discursiva e descontraída (no sentido de dar espaço às inquietações dos aprendizes e não guiá-los de acordo com as intenções do professor) se faz necessário para se quebrar a imagem negativa dessas aulas que os estudantes trazem do ensino da língua materna. Vale ressaltar que não parece ser próprio do jovem brasileiro dedicar-se à leitura e, quando somamos a isso a ausência e/ou ineficiência do sistema de ensino de literatura na Educação Básica, a situação agrava-se, tornando-se ainda mais preocupante. Assim, com esse procedimento metodológico, temos a chance de levar os aprendizes a sentirem o prazer da leitura literária e se, em situações propícias, os levarmos a fazer uma ponte entre a literatura de língua estrangeira e a literatura brasileira podemos, inclusive, fazê-los ver a literatura de outro modo, despertá-los para um envolvimento prazeroso com o TL.

Ao trabalhar com o texto literário em uma aula de leitura, por exemplo, o professor consegue trabalhar diversas frentes do ensino de línguas. O próprio ato de ler, já fornece espaço para se explorar a expressão oral dos estudantes: o professor pode conduzí-los a perceber que determinados fonemas tem certo ritmo de pronúncia e que, em algumas vezes, quando não se atenta para isso, a palavra muda de significado quando pronunciada de outra forma, esse procedimento pode confluir para o aprimoramento da compreensão oral. Quando se conhece uma palavra nova, o aprendiz tanto percebe questões de ortografia, quanto aumenta o seu vocabulário.

Necessariamente, essas mesmas questões podem ser trabalhadas com outros gêneros textuais como a notícia de jornal ou um anúncio publicitário de uma revista. Mas o diferencial de se utilizar o texto literário é, justamente, poder trabalhar tudo isso associado ao cultural. A literatura, não importa de qual língua ou nacionalidade seja, é, em geral, tida como a expressão máxima e consagrada daquele idioma, sendo usada como exemplo de utilização do padrão culto de uma língua. No Brasil, por exemplo, por muitos anos os clássicos de nossa literatura eram usados nas aulas de língua portuguesa com a finalidade de mostrar a forma vista como correta de escrever e falar o português. Possibilitar esse encontro do aprendiz com a cultura do outro através da língua é interessante quando se pensa em formar não apenas sujeitos capazes de se comunicar em LE, mas sujeitos capazes de serem críticos em relação àquilo que aprendem. $\mathrm{O}$ uso adequado do TL no ensino de língua estrangeira 
justifica-se pela possibilidade de contemplar temas relacionados a comportamentos, valores e costumes de diversas nações, diferentes formas de expressão linguística, provenientes de vários países e grupos sociais, questões identitárias em âmbito individual ou coletivo, que são representados em textos literários, caracterizando o espaço de aprender uma segunda língua como uma possibilidade de ter acesso ao universo cultural que a circunda. (MOTA, 2010, p. 103)

Com isso, o que se propõe é utilizar os textos literários, em sala de aula, para se trabalhar além da função comunicativa e das funções linguísticas, para que se encontre um modo de abrir espaço para as discussões de temas inerentes a esses textos. Em outras palavras, é trabalhar o lado "sujeito inserido num mundo globalizado" dos estudantes, para que dessa forma eles possam conhecer a cultura do outro e relacionar com a sua, ver a língua estrangeira, mas também conhecer o estrangeiro falante dessa língua.

\section{Uma proposta de trabalho: ensino de língua e fábulas de La Fontaine em aula de FLE}

Toda a discussão sobre o histórico do ensino de língua estrangeira associado à literatura, os porquês e os benefícios dessa relação, servem para fundamentar e justificar a importância deste trabalho. De acordo com as considerações realizadas até agora, trazemos uma proposta de trabalho que associa língua e literatura no ensino de língua estrangeira (no caso, a língua francesa) pelos caminhos das fábulas de La Fontaine.

Não obstante inúmeras discussões sobre a abordagem do texto literário em aula de línguas e, principalmente, neste caso, a estrangeira, o nosso posicionamento é de que essa estratégia de aprendizagem é vital, visto que "de todos os gêneros literários, provavelmente, é a poesia o menos prestigiado no fazer pedagógico da sala de aula" (PINHEIRO, 2006, p. 15), e também por que

proposições de trabalho com o texto literário para principiantes em língua francesa são relativamente escassas. Para alunos de níveis avançados é provável que essa abordagem seja mais comum, por isso dispusemo-nos a desenvolver tal perspectiva, o que do nosso ponto de vista tem sido percebido como um desafio (PINHEIRO-MARIZ, 2007, p. 117).

Conforme já frisado, essa proposta foi pensada a fim de se trabalhar com as fábulas $L a$ cigale et la fourmi, La colombe et la fourmi e La mouche et la fourmi, de Jean de La Fontaine. Tal proposta pode ser aplicada em uma turma de FLE (preferencialmente, de iniciantes) e que, a depender do tempo de cada aula, pode ser dividida e realizada em mais de um encontro. 
Dessa forma, o professor pode adaptá-la conforme as condições e realidade de sua turma. Todavia, esta atividade foi pensada em um período em torno de 90 (noventa) minutos de aula.

O seu objetivo principal é instigar a capacidade interpretativa do aprendiz, além de levá-lo a conhecer um pouco do estilo do autor, aumentar seu vocabulário, entre outros aspectos. Assim, nesta abordagem, buscamos incitar à busca da seguinte questão: Qual é a crítica que La Fontaine faz, em suas fábulas, à sociedade de sua época através da personagem “formiga"? Ao apresentar a nossa sugestão de trabalho, trazemos considerações sobre o autor das fábulas, uma vez que julgamos necessário conhecer o autor da obra e a sua importância para a literatura francesa e para a sua época. Apresentamos ainda uma breve leitura e interpretação das fábulas, com o propósito de oferecer um auxílio teórico-prático para o procedimento de abordagem e aplicação desta proposta.

\subsection{La Fontaine e suas fábulas}

Jean de La Fontaine (1621-1695) foi poeta e fabulista francês. Sua produção se caracteriza pela forma perspicaz como critica a sociedade europeia da época, utilizando a ironia e a metáfora por meio de histórias, cujos principais personagens eram animais. O seu estilo cativou e ainda cativa muitas crianças por todo o mundo, fazendo de La Fontaine um dos mais famosos fabulistas da história da literatura no mundo. Ainda hoje as suas fábulas são relidas e reescritas, sinalizando a flexibilidade desse gênero. (OLIVEIRA, 2011).

Seus textos são escritos em forma rimada, musical e, geralmente, em pequenos versos a fim de facilitar a memorização das histórias e de suas morais (lições que se pode depreender do texto para a vida do leitor), uma das características das fábulas. De acordo com Fiorin (1986/1987) “o que elas [as fábulas] ensinam não está contido na "moral”, que revela sempre que o mundo dos homens não é regido por belos ideais, mas pela força, pela astúcia, pelos interesses" (FIORIN, 1986/1987, p. 86).

Não traremos aqui os textos integrais das fábulas de nosso estudo tendo em vista que algumas são longas e que todas são facilmente encontradas. Traremos uma breve análise poética, seguida de uma proposta de interpretação de cada uma das fábulas.

\subsubsection{Fábula 1: La cigale et la fourmi}

A famosa fábula A cigarra e a formiga é composta por 22 versos, formados por rimas parelhadas (AABBCC...GG) do primeiro ao décimo quarto verso e por rimas interpoladas 
(HIIHJKKJ) do décimo quinto ao vigésimo segundo verso. De um modo geral, os versos são heptassílabos, com raras exceções. As rimas são ricas, formadas por adjetivos e substantivos, e quanto às figuras de linguagem do texto, é possível encontrar a metáfora e a ironia, com a finalidade de intensificar a fala e os sentimentos da formiga. Por ser pequena tanto no tamanho dos versos e no tamanho total, é uma fábula que parece ser fácil de decorar e, assim, no eixo da oralidade, pode ser transmitida a outras pessoas.

Em termos interpretativos, temos nessa fábula a história de um cigano (representado pela cigarra), que tinha uma vida boêmia, regulada em cantorias, danças e divertimentos. Chegado o inverno, tempo em que as condições de sobrevivência são críticas ${ }^{1}$, sobretudo, por causa do intenso frio, ele se vê desprovido de mantimentos e sabe que perecerá se não encontrar ajuda. Então, decide bater à porta de seu vizinho (representado pela formiga) que por ter trabalhado, arduamente, durante todo o verão, está agora tranquilo em sua casa. Tendo conhecimento de que o cigano (a cigarra) é o único culpado pela própria desgraça, o vizinho (a formiga) diz que tal situação não lhe dizia respeito. Nos termos da própria fábula:

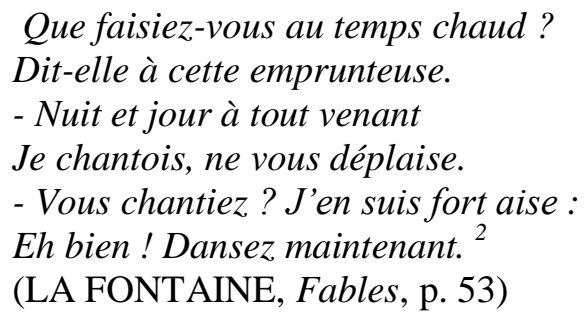

A fala final da formiga é construída com todo um arcabouço cômico, quando o autor apresenta um jogo entre as palavras "chanter" (cantar) e "danser" (dançar). Temos aqui um exemplo do sentido denotativo e do conotativo, respectivamente. Outro ponto a se observar, ainda, são os adjetivos utilizados na fala do narrador "emprunteuse", (agiota) que caracterizam não só o personagem da fábula, mas também diz da pessoa a quem a crítica se dirige por parte do autor.

\subsubsection{Fábula 2: La colombe et la fourmi}

A fábula $A$ pomba e a formiga é escrita em rimas irregulares (ABBCDEED...) e composta por 19 versos, sendo eles heptassílabos (1), octassílabos (4) ou alexandrinos (14).

\footnotetext{
${ }^{1}$ Nesse momento já se percebe uma possibilidade de estimular os diálogos interculturais. Deve-se despertar no aprendiz a curiosidade por fatores tais como clima e natureza.

2 “- No verão, em que lidavas?- / À pedinte, ela pergunta./ Responde a outra: - Eu cantava / Noite e dia, a toda hora. / -Oh! Bravo! - torna a formiga - / Cantavas? Pois dança agora!'(tradução de Fábulas de La Fontaine, 1968, p. 20)
} 
Esta, como as outras fábulas em estudo, não traz a moral de forma explícita, outra diferença entre as fábulas de La Fontaine. Nessa fábula, ele deixa claro que utiliza os animais para instruir os homens ao dizer logo no início: "L'autre exemple est tiré d'animaux plus petits" (idem, p. 88).

La colombe et la fourmi apresenta três personagens: a pomba, a formiga e o "croquant" . A pomba, ao sentir sede, decide ir beber água em um riacho e, então, percebe que uma formiga está se afogando e não conseguirá salvar-se sozinha. Logo, a pomba pega um ramo e usa-o para salvar a vida da companheira. Porém, nesse instante, quem está com a vida ameaçada é a pomba, pois o croquant se aproxima armado, pronto para matá-la. Mesmo diante de um ser milhares de vezes maior do que ela, a formiga não se deixa intimidar e parte para combater o inimigo, subindo pela sua calça e picando-o. Distraído com a formiga, o croquant desvia a atenção da pomba, que aproveita a deixa para escapar a salvo.

Uma das leituras dessa fábula possíveis de ser realizada, é que La Fontaine mostra que uma pessoa pode fazer muito mais do que os outros supõem que ela pode ser, e que são aqueles considerados os menores (e aqui não se fala em tamanho, mas em posição social) que mais podem surpreender a todos. Ou seja, o autor mostra aqui que o povo, a massa popular de sua época, poderia sim inquietar os grandes senhores de seu tempo e lutar por melhores condições sociais.

\subsubsection{Fábula 3: La mouche et la fourmi}

Já em A mosca e a formiga, as rimas não apresentam uma sequência rítmica (ABAB...DEDEEE...) e são predominantemente pobres. Sobre as figuras de linguagem, a fábula é carregada de ironia e de metáforas. Esse tipo de linguagem serve para intensificar as ações das personagens e da maneira linguística como eles se expressam.

Aqui, "le prix" é o valor de cada personagem. Uma tenta mostrar que é mais importante que a outra, apresentando diversos argumentos. A mosca ressalta que ela é mais nobre que a formiga, porque ela frequenta lugares luxuosos (como os palácios) enquanto a formiga não, seja por querer, seja por poder. Mas a formiga não se deixa humilhar e mostra que a mosca não passa de uma exibicionista. Ela deixa transparecer toda a sua humildade e ignora as provocações da mosca, dando-lhe uma verdadeira lição de moral. Diz o texto:

\footnotetext{
${ }^{3}$ Não iremos entrar em discussão sobre os problemas de tradução e cultura que cercam o texto, mas "croquant" pode ser compreendido como um proprietário de terras que, por não ter um espantalho em meio à sua plantação, tem que percorrê-la a pé para afugentar as aves que comprometem o cultivo.
} 
[...] Vous fassiez sonner vos mérites ?

Nomme-t-on pas aussi mouche les parasites?

Cessez donc de tenir un langage si vain :

N'ayez plus ces hautes pensées.

[...] Alors, je jouirai du fruit de mes travaux ;

Je n'irai, par monts ni par vaux,

M'exposer au vent, à la pluie ;

Je vivrai sans mélancolie :

[...] Adieu : je perds le temps ; laissez-moi travailler ;

Ni mon grenier, ni mon armoire,

$\mathrm{Ne}$ se remplit à babiller ${ }^{4}$

(La Fontaine, Fables, p. 126)

Dessa forma, o autor mostra que quem está por cima (representado pela mosca) quer ser o centro do universo, maior e melhor que os outros (aqui representado pela formiga), mas são esses outros, que estão por baixo, que sabem ver a vida por outro ângulo, pelo ângulo da realidade.

\subsection{Proposta de trabalho}

Já foi expressa, em sessões acima, a necessidade de se elaborarem propostas de trabalho que envolvam o ensino de língua com a literatura. Após essa breve leitura (dentre tantas possíveis) dessas três fábulas de La Fontaine, trazemos agora uma sugestão de atividade que realiza esse envolvimento.

Essa proposta trabalha com as quatro competências linguísticas (compreensão escrita e oral; compreensão e expressão oral) no nível iniciante (A1 e A2, segundo o CECRL, 2001), e com as quatro no nível intermediário (B1 e B2), enfocando-se, nesse caso a expressão escrita $^{5}$. Quanto aos conteúdos passíveis de abordagem, citamos: i) Estudo de versos, rimas e métrica; ii) Figuras de linguagem; iii) A voz do personagem (La mouche et la fourmi) e do narrador (La colombe et la fourmi e La cigale et la fourmi); iv) Tempos verbais: Présent de l'indicatif, Passé Composé, Présent conditionel (La mouche et la fourmi); v) Gênero e número dos nomes (substantivos e adjetivos), entre outros.

\footnotetext{
4 “- Fazes ressoar teus próprios méritos?/ - Não é também a mosca um parasita? / - Pare, então, de ter uma linguagem tão vã: / - Não tenhas mais esses pensamentos altos./ [...] - Então, eu me alegrarei com os frutos do meu trabalho; / - Não irei por montes nem por vales / - Me expor ao vento e à chuva / - Viverei sem melancolia: / [...] - Adeus: estou perdendo meu tempo; deixe-me trabalhar / - Nem meu celeiro, nem meu armário / - Estão cheios de murmúrios" (tradução nossa).

${ }^{5}$ Alguns estudiosos com Ridd, (2000, apud. CORDEIRO, 2006) afirmam que além de ler, escrever, falar e ouvir, traduzir também deveria ser considerada uma das competências linguísticas nesse processo de ensinoaprendizagem, caso o professor espere que o aluno consiga desenvolver uma comunicação intercultural efetiva.
} 


\subsubsection{Preparação e execução da atividade}

É evidente que antes de qualquer procedimento, o professor deve ler e estudar os textos que serão trabalhados, conhecendo o léxico e o sentido dos textos. O professor deve preparar cópias suficientes para a turma: de modo que todos os aprendizes recebam as três fábulas. Porém, classe será dividida em três grupos e cada um trabalhará com uma fábula diferente. Seria interessante também que o professor elaborasse questões sobre as fábulas; não para tomá-las como roteiro interpretativo com respostas previamente elaboradas e tidas por “certas"; mas, apenas para direcionar os debates sobre elas caso os estudantes se mostrem tímidos, ao expressarem-se na língua estrangeira ou caso não queiram expor suas impressões sobre o texto.

Definidos os grupos (seja por sorteio, seja por escolha dos próprios aprendizes), o professor deverá distribuir as fábulas: uma fábula para cada grupo. Feito isso, ele transmitirá as informações necessárias para o bom andamento da atividade. Inicialmente o trabalho deve ser realizado em grupo. As informações são as seguintes:

$\checkmark$ Os estudantes devem ler as fábulas juntos (entre os grupos) sem, em primeiro momento, utilizarem dicionário. Portanto, devem estar atentos para as características do gênero: rimas, musicalidade, tipos de versos. Essa percepção deve ser feita pelos próprios aprendizes, sem ajuda direta do professor. Porém, isso dependerá do nível da turma e/ou do objetivo do professor;

$\checkmark$ Os estudantes devem buscar nos textos, após essa leitura mais externa e estrutural, identificar as características de cada animal, buscando desvendar o motivo pelo qual eles foram utilizados, ou seja, qual a função deles na construção da mensagem da fábula;

$\checkmark$ Em associação ao passo anterior, os participantes devem perceber a presença de figuras de linguagem e quais são utilizadas nos textos;

$\checkmark$ Por fim, devem associar a moral ou intenção do texto, uma vez que não há moral explícita, com a realidade da época em que o texto foi escrito e com a dos dias atuais.

Após os grupos terem reunido todas essas informações, passa-se à socialização do conhecimento. Cada grupo deverá indicar um leitor e um porta-voz (ou dividir as funções entre mais pessoas). Cada grupo, por vez, realizará a leitura em voz alta e todos os demais o acompanham. O professor supervisionará a leitura e corrigirá os eventuais deslizes (fautes) cometidos pelo leitor. Finalizada a leitura, o leitor irá expor a análise (evidentemente, na 
língua estrangeira) da fábula trabalhada pelo seu grupo e, em seguida, o professor inicia as discussões sobre o texto apresentado. Esse processo deverá ser repetido pelos três grupos.

Ao final da discussão individual de cada texto, o professor $^{6}$ deverá levantar uma discussão sobre o contexto geral das obras, envolvendo também o autor e conduzindo os estudantes a levantarem hipóteses que os levem a responder a questão principal da atividade, que agora, deve ser levantada pelos aprendizes: Qual é a crítica que La Fontaine faz em suas fábulas à sociedade de sua época através da personagem "formiga"?

Concluídos estes passos, o professor poderá solicitar outros exercícios inerentes a este trabalho como atividades extraclasse ou a serem realizados em casa e entregues na aula seguinte, os quais poderão ser utilizados como requisitos avaliativos, parciais ou completos, da turma.

\subsubsection{O pós-atividade}

A atividade aqui proposta foi pensada para ser aplicada, preferencialmente, em uma turma iniciante de FLE, entretanto, nada impede que seja realizada em turmas mais avançadas. Pensando assim, quanto aos exercícios inerentes a esta proposta de aula, levantamos ainda duas sugestões de atividades de acordo com os diferentes níveis de estudo.

A primeira se aplica aos estudantes de turmas iniciantes que, nos termos do Cadre européen commun de référence pour les langues (CECRL), podem ser chamadas de classes de níveis A1 ou A2 (CECRL, 2001). Para esses aprendizes, o professor pode solicitar que eles individualmente ou em grupo pesquisem e tragam outras fábulas do próprio La Fontaine ou de outros autores, que versem sobre o mesmo tema da fábula trabalhada quando organizados em grupos no início da atividade. Pensando no intercultual, o professor poderia aproveitar tal atividade e solicitar que os aprendizes pesquisassem, na literatura brasileira, fábulas com mesma linha de interpretação e/ou estilo de escrita. Estas seriam passadas aos colegas na aula seguinte.

Para os estudantes de nível B1 (CECRL, 2000), por exemplo, ou de níveis ainda mais avançados, seria conveniente que praticassem a expressão escrita, produzindo um artigo de opinião ou outro tipo de texto argumentativo, abordando a questão da crítica social dos textos, tendo as discussões realizadas em classe como ponto de partida para a atividade escrita.

\footnotetext{
${ }^{6}$ Pensamos, aqui, o professor sempre como aquele que pode nortear as discussões. Porém, nada impede que tais atitudes, iniciativas, partam dos próprios estudantes.
} 


\subsection{Considerações sobre atividades de leitura}

Trazemos, agora, algumas reflexões sobre a atividade de leitura das fábulas, em uma perspectiva que reúne Língua e Literatura, pelos caminhos da didática das línguas. A interpretação que aqui apresentamos é apenas uma dentre tantas possíveis. Afirmamos isso de acordo com os postulados da Análise do Discurso de linha francesa, na qual acreditamos ter muito a contribuir para as aulas de leitura tanto em língua materna, quanto em língua estrangeira. Dessa forma, chamamos a atenção do professor para se fazer atento a essas considerações durante a execução da aula que propomos aqui. Quando afirmamos que o professor poderia elaborar um roteiro, logo, especificamos que este não deveria ser utilizado para conduzir a interpretação em apenas uma linha, mas que fosse usado no caso específico em que os aprendizes se mostrem acanhados ou pouco interessados.

Aconselhamos o professor a evitar silenciar os seus aprendizes. É possível que, em princípio, eles percebam apenas o superficial do texto, ou seja, que interpretem o texto pelo o que nele está: histórias fictícias de animais. Porém, é possível também que eles consigam compreender a profundidade e abrangência que estes textos possuem e que possam inclusive encontrar algo que fugiu à interpretação que demos aqui ou até mesmo à do professor. Sugerimos, pois, que se permita a participação do aprendiz de modo aberto e sem imposições ou limitações, pois acreditamos se a execução da atividade estiver relacionada à imposição, que tal procedimento poderá comprometer, em algum momento, o adequado desenvolvimento da proposta que sugerimos. Por isso, acreditamos que, em trabalhos desse tipo, o professor deverá desempenhar apenas o papel de guia.

Mesmo se aplicada em turmas iniciantes, o pouco domínio da língua francesa não deve ser visto como empecilho, mas como oportunidade de trabalhar a oralidade. Coracini (2002), no texto "A aula de leitura: um jogo de ilusões", ao observar aulas de leitura de uma turma de Francês Instrumental constata que muitas vezes, o estudante se vê limitado pelo pouco conhecimento da língua francesa e se deixa guiar pela leitura do professor, que ele julga ser a "correta", e sugere:

Caberia ao professor, através de uma metodologia menos diretiva e dominadora, que contemplasse o aluno como ser pensante e crítico, criar situações, por exemplo, de comparação entre vários textos produzidos a partir de um mesmo fenômeno ou evento para não apenas buscar as diferenças formais e linguísticas, mas sobretudo culturais, essas muitas de 
cunho ideológico e que, evidentemente, determinam a materialidade linguística.

[...] Caberia ao professor, enfim, permitir que se questionem as verdades que parecem "naturais", inquestionáveis; que se desmistifique o estrangeiro, mostrando as diferenças culturais que se asseguram a identidade brasileira, ao invés de anulá-la. Mas, para isso, é preciso que o professor passe a questionar essas mesmas verdades, a metodologia, o material didático, suas próprias atitudes em função do objetivo mais importante que deveria nortear todo o ensino qual seja o de colaborar com o aluno para que ele tenha a possibilidade de se auto-observar (na medida do possível) e se posicionar criticamente no mundo. (CORACINI, 2002, p. 32)

Mais uma vez, vemos a reflexão sobre a necessidade de o professor estar sempre em busca de caminhos para executar o seu fazer docente. A auto reflexão dever ser o elemento norteador nas mais diversas atividades em sala de aula e leitura literária pode, mais que outros tipos de textos, favorecer leituras múltiplas.

\section{Considerações finais}

Depois dessas reflexões, podemos ratificar que as fábulas de La Fontaine são muito mais que simplesmente histórias de animais. Seus textos comportam um grande valor crítico e moral que abrange não só a condição da sociedade da época em que foram escritos, mas trazem uma crítica atual, que pode facilmente ser aplicada aos dias de hoje. Mesmo sendo textos baseados na obra de Esopo, La Fontaine conseguiu adaptá-los a realidade de seu tempo e, com grande maestria, fazê-los mundialmente conhecidos.

Dispomo-nos no início deste texto a responder a seguinte questão: Qual é a crítica que La Fontaine faz em suas fábulas à sociedade de sua época através da personagem "formiga"? Como resposta, podemos dizer que a formiga nessas fábulas é usada para representar a classe trabalhadora, pobre e humilhada, que sofre exploração daqueles que são os senhores de tudo (representados pela mosca) ou daqueles que nada fazem (como representado pela cigarra), que acabam, muitas vezes, sendo ambas as mesmas pessoas. A formiga é um ser trabalhador, que combate as dificuldades da vida sem se deixar abater por elas, que sabe o seu lugar e a sua realidade.

Na perspectiva do ensino e aprendizagem de LE, compreendemos que o uso de textos literários em aula, especificamente de Francês, é bastante interessante e importante, pois como afirma Pinheiro-Mariz (2008, p. 181): “Trabalhar o TL em aula LE é uma forma bastante profícua de exercitar o respeito ao outro, pois além de conhecer outra língua, [...], 
promovendo o respeito à sua própria; eis, então uma visão moderna no ensino de LE”, além de promover um necessário retorno às origens do ensino de línguas.

Para concluir, defendemos ainda que o ensino de línguas deve estar associado ao ensino da literatura dessas línguas, pois são muitos os benefícios de tal casamento. Encerramos este texto, fazendo nossas as palavras de Mota (2010):

\begin{abstract}
No ensino de qualquer outra língua, a literatura apresenta-se como um meio profícuo para adentrar questões culturais que enriquecem as aulas e abrem as suas margens para considerar aspectos que redimensionam o ensino de língua. Um ensino de língua que não deve ser visto, simplesmente, como a transmissão de um conjunto de termos e expressões voltadas para a comunicação em nível pragmático, mas, sim, como uma forma de também aprender a gama complexa de representações culturais abarcadas em signos verbais e não verbais, que trazem em seu bojo (re) leituras sobre o "eu" e o outro. (MOTA, 2010, p. 110)
\end{abstract}

Acreditamos que a prática da leitura literária no âmbito da sala de aula de língua estrangeira pode ser um espaço importante para debates sobre questões diversas tais como as questões ligadas às representações culturais, estimulando, dessa forma, uma maior amplitude do universo da linguagem.

\title{
6. Referências
}

BARTHES, Roland. Le plaisir du texte. Éditions Seuil: Paris, 1973.

CADRE EUROPEEN COMMUN DE REFERENCE POUR LES LANGUES. Le Cadre européen commun de référence pour les langues: apprendre, enseigner, évaluer. Strasbourg, Division des Politiques Linguistiques. 2000.

CORACINI, Maria José Rodrigues Faria. A aula de leitura: um jogo de desilusões. In: CORACINI, M. J. R. F. (Org.). O jogo discursivo na sala de leitura: língua materna e língua estrangeira. 2 ed. Campinas - SP: Pontes, 2002. p. 27 - 33.

CORDEIRO, Juci Mara. Estratégias para o processo tradutório. Anais do VI Encontro do Círculo de Estudos Linguísticos do Sul. Florianópolis, 2006.

FIORIN, José Luiz. Millôr e a destruição da fábula. In.: Alpha: revista de Linguística. Araraquara: Periódico da Universidade Estadual Paulista. v. 30/31. 1986/1987, p. 85 - 94.

FONTAINE, Jean de La. Fables. Paris, Pocket, 1989.

MONTEIRO, Andréia Cardoso. Fábula no livro didático: um gênero em (des)uso?. Anais do $4^{\circ}$ Simpósio Internacional de Estudos de Gêneros Textuais. Universidade do Sul de Santa Catarina. vol. 4, 2007, p. 589 - 597.

MOTA, Fernada. Literatura e $(m)$ ensino de língua estrangeira. Fólio - Revista de Letras. v. 2, n. 1. Vitória da Conquista, 2010, p. $101-111$. 
PINHEIRO, Hélder. Poesia em sala de aula. 2. ed. João Pessoa : Idéia, 2006.

PINHEIRO-MARIZ, Josilene. O texto literario em aula de francês língua estrangeira (FLE). Tese de Doutorado apresentada ao Programa de Pós-Graduação em Língua e Literatura Francesa da Universidade de São Paulo (USP). São Paulo, 2007.

Panorama do ensino da literatura de língua francesa em contexto exolingue. Revista Leia Escola. Periódico do Programa de Pós-Graduação em Linguagem e Ensino da Universidade Federal de Campina Grande. v. 9, n. 1, 2009, p. 97 - 115.

OLIVEIRA, Maria Angélica de. Caminhos da fábula: literatura, discurso e poder. Bagagem: Campina Grande. 2011.

SANTORO, Elisabetta. Da indissociabilidade entre o ensino de língua e de literatura: uma proposta para o ensino de italiano como língua estrangeira em cursos de Letras. Tese de Doutorado apresentada ao Programa de Pós-Graduação em Linguística da Universidade de São Paulo (USP). São Paulo, 2007.

VALENTE, Marcela Iochem; PINHEIRO, Rosane de Sena. Língua e literatura: uma parceria de sucesso no mundo das Letras. Revista FACEVV. Periódico da Faculdade Ceneticista de Vilha Velha. v.1, n.1, 2008, p. $52-57$. 